\title{
Hydrothermally Synthesized Nanostructured LiMnxFe1-xPO4 (x = 0-0.3) Cathode Materials With Enhanced Properties for Lithium-Ion Batteries
}

\section{Dung V. Trinh}

School of Chemical Engineering, Hanoi University of Science and Technology

\section{Mai T. T. Nguyen}

School of Chemical Engineering, Hanoi University of Science and Technology

Hue T. M. Dang

School of Chemical Engineering, Hanoi University of Science and Technology

Dung T. Dang

School of Chemical Engineering, Hanoi University of Science and Technology

Hang T. T. Le

School of Chemical Engineering, Hanoi University of Science and Technology

Huynh T. N. Le

Faculty of Chemistry, VNUHCM-University of Science, 227 Nguyen Van Cu Street, Ho Chi Minh City, Vietnam

\section{Hoang V. Tran}

School of Chemical Engineering, Hanoi University of Science and Technology

Chinh D. Huynh ( $\nabla$ chinh.huynhdang@hust.edu.vn )

School of Chemical Engineering, Hanoi University of Science and Technology

\section{Research Article}

Keywords: Hydrothermal route, Olivine LiMnxFe1-xP04, Cathode materials, Li-ion batteries

Posted Date: February 19th, 2021

DOI: https://doi.org/10.21203/rs.3.rs-209800/v1

License: (c) (i) This work is licensed under a Creative Commons Attribution 4.0 International License. Read Full License 


\section{Hydrothermally synthesized nanostructured $\mathrm{LiMn}_{x} \mathrm{Fe}_{1-\mathrm{x}} \mathrm{PO}_{4}(x=0-0.3)$}

2 cathode materials with enhanced properties for lithium-ion batteries

Dung V. Trinh ${ }^{1}$, Mai T. T. Nguyen ${ }^{1}$, Hue T. M. Dang ${ }^{1}$, Dung T. Dang ${ }^{1}$, Hang T. T. Le ${ }^{1}$, Huynh T. N. Le ${ }^{2}$, Hoang V. Tran ${ }^{1}$, Chinh D. Huynh ${ }^{1, *}$

Road, Hanoi, Vietnam

${ }^{2}$ Faculty of Chemistry, VNUHCM-University of Science, 227 Nguyen Van Cu Street, Ho Chi Minh

\footnotetext{
*Corresponding author: Email: chinh.huynhdang@hust.edu.vn (C.D. Huynh)
} 


\section{Abstract}

26 Nanostructured cathode materials based on Mn-doped olivine $\mathrm{LiMn}_{\mathrm{x}} \mathrm{Fe}_{1-\mathrm{x}} \mathrm{PO}_{4}(x=0,0.1,0.2$, and 0.3$)$

27 were successfully synthesized via a hydrothermal route. X-ray diffraction (XRD), energy-dispersive

28 X-ray spectroscopy (EDS), field-emission scanning electron microscopy (SEM), and Raman

29 spectroscopy indicated that the synthesized samples possessed a sphere-like nanostructure and a

30 relatively homogeneous size distribution in the range of $100-200 \mathrm{~nm}$. Electrochemical experiments

31 and analysis showed that the Mn doping increased the redox potential and boosted the capacity. While

32 the undoped olivine $\left(\mathrm{LiFePO}_{4}\right)$ had a capacity of $169 \mathrm{mAh} \mathrm{g}^{-1}$ with a slight reduction $(10 \%)$ in the

33 initial capacity after 50 cycles $\left(150 \mathrm{mAh} \mathrm{g}^{-1}\right)$, the $\mathrm{Mn}$-doped olivine samples $\left(\mathrm{LiMn}_{\mathrm{x}} \mathrm{Fe}_{1-\mathrm{x}} \mathrm{PO}_{4}\right)$

34 demonstrated reliable cycling tests with negligible capacity loss, reaching 151, 147, and $157 \mathrm{mAh} \mathrm{g}^{-1}$

35 for $x=0.1,0.2$, and 0.3 , respectively. The results from electrochemical impedance spectroscopy (EIS)

36 accompanied by the galvanostatic intermittent titration technique (GITT) confirmed that the Mn

37 substitution for Fe promoted the charge transfer process and hence the rapid Li transport. These

38 findings indicate that the $\mathrm{LiMn}_{x} \mathrm{Fe}_{1-\mathrm{x}} \mathrm{PO}_{4}$ nanostructures are promising cathode materials for lithium

39 ion battery applications.

41 Keywords: Hydrothermal route; Olivine $\mathrm{LiMn}_{x} \mathrm{Fe}_{1-x} \mathrm{PO}_{4}$; Cathode materials, Li-ion batteries 
50 The production and storage of new and clean energy are two major challenges that face humanity to

51 stop the depletion of natural resources. In modern life, a wide range of systems such as portable

52 electronic devices, computers, phones, cameras, and electric vehicles require stable and safe electrical

53 energy. Such diversity in the electronics market compels the development of different electrochemical

54 systems such as non-flammable batteries, superconductors, and other types of batteries [1-5]. Since

55 1970, the phosphorus-olivine structure has been tapped as a potential material for Li-ion batteries [6-

56 10]. In particular, lithium iron phosphate $\left(\mathrm{LiFePO}_{4}\right)$ and lithium manganese phosphate $\left(\mathrm{LiMnPO}_{4}\right)$ are

57 some of the most studied among transition metal oxide cathode materials due to their high theoretical

58 capacity ( $\square 170 \mathrm{mAh} \mathrm{g}^{-1}$ ), inherent chemical stability, increased safety due to their lower explosion

59 risk from overcharging, better thermal stability, and lower material cost [11-14]. However, the

60 conductivity $(\square)$ and $\mathrm{Li}$-ion diffusion coefficient of $\mathrm{LiFePO}_{4}$ and $\mathrm{LiMnPO}_{4}$ are on the low end of the

61 spectrum; for example, $\square \mathrm{LiFePO} 4=10^{-8}-10^{-9} \mathrm{~S} \mathrm{~cm}^{-1}$ and $\square \mathrm{LiMnPO} 4=10^{-10} \mathrm{~S} \mathrm{~cm}^{-1}[12,14-16]$. Due to the

62 disadvantage of these materials' conductivity on electronics and ion transport, there exists a major

63 constraint to commercial applications of these materials [17, 18]. To mitigate these issues, three

64 approaches are typically considered: (i) coating carbon on the surface of olivine to improve the electron

65 transfer process; (ii) substituting Fe with a 3d-metallic element, and (iii) reducing the particle size to

66 the nanoscale with different particle shapes like nanoparticles, nanorod plates, and nanorectangular

67 sheets $[1,13,19-23]$. Some studies have shown that cation mixing in $\mathrm{LiMn}_{\mathrm{x}} \mathrm{Fe}_{1-\mathrm{x}} \mathrm{PO}_{4}$ orthophosphates

68 is a great trade-off between the valuable capacity of $\mathrm{LiFePO}_{4}$ and the high potential of $\mathrm{LiMnPO}_{4}$

69 (voltage of oxidation pair compared with $\mathrm{Li}^{+} / \mathrm{Li}$ )[20, 24, 25]. Other studies have also shown that doping

70 metal cations into $\mathrm{LiFePO}_{4}$ or $\mathrm{LiMnPO}_{4}$ causes a narrowing of the energy gap, which may improve

71 the electrical conductivity of this material $[3,25]$. On the other hand, to achieve high electrochemical

72 efficiency in olivine phosphate cathode materials, several methods of nanomaterial synthesis have been

73 employed, such as solid-state reactions [1, 26], sol-gel methods [13, 27], and reactions from 
74 hydrothermal routes [11, 21, 23, 28, 29]. Among these methods, the hydrothermal synthesis is a facile

75 water-based precipitation technique that enables the control of the nucleation and development of the 76 crystal.

In this work, we prepared the nano-olivine structure $\mathrm{LiMn}_{x} \mathrm{Fe}_{1-\mathrm{x}} \mathrm{PO}_{4}(\mathrm{x}=0,0.1,0.2$, and 0.3$)$

78 by a facile hydrothermal route, and the as-prepared olivines were coated with carbon through pyrolysis.

79 Electrochemical studies showed that the olivines were capable of delivering a reversible capacity

80 around $160 \mathrm{mAh} \mathrm{g}^{-1}$ at a current density of $\mathrm{C} / 10$ in the voltage range of $2.5-4.3 \mathrm{~V}\left(\mathrm{vs} . \mathrm{Li}^{+} / \mathrm{Li}\right)$. The

81 kinetics of Li transport in these olivines were also discussed.

\section{2. Experimental}

83 The chemicals $\mathrm{Mn}\left(\mathrm{NO}_{3}\right)_{2}$ ( $\square 99$ wt.\%), $\mathrm{FeSO}_{4} .7 \mathrm{H}_{2} \mathrm{O}$ ( $\square 99$ wt.\%), $\mathrm{LiOH}$ ( $\square 98$ wt.\%), $\mathrm{NH}_{3}$ solution 84 (30 wt.\%), $\mathrm{H}_{3} \mathrm{PO}_{4}(\square 85 \%)$, citric acid monohydrate $\left(\mathrm{C}_{6} \mathrm{H}_{8} \mathrm{O}_{7} . \mathrm{H}_{2} \mathrm{O}, \square 99.5 \%\right.$ wt.), polyvinylidene 85 fluoride (PVDF), ethylene carbonate (EC, 98 wt.\%), and dimethyl carbonate (DMC, $\square 99$ wt.\%) were 86 purchased from Sigma-Aldrich. All the other chemicals were of analytical grade and used without 87 further purification. All the aqueous solutions were prepared with deionized water (DI water, 18.2 $88 \mathrm{M} \Omega . \mathrm{cm})$ for all the experiments.

90 Synthesis of olivine samples

91 A mixture of $\mathrm{H}_{3} \mathrm{PO}_{4}, \mathrm{Mn}\left(\mathrm{NO}_{3}\right)_{2}, \mathrm{FeSO}_{4} .7 \mathrm{H}_{2} \mathrm{O}$, and $\mathrm{C}_{6} \mathrm{H}_{8} \mathrm{O}_{7} \cdot \mathrm{H}_{2} \mathrm{O}$ were dissolved into $50 \mathrm{~mL}$ DI water 92 under $\mathrm{N}_{2}$ atmosphere at 1:9, 2:8, and 3:7 molar ratios of Mn:Fe. Then, $20 \mathrm{~mL}$ of $0.5 \mathrm{M} \mathrm{LiOH}$ was 93 dropped into the mixture at a 3:1 ratio of $\mathrm{Li}^{+}: \mathrm{PO}_{4}{ }^{3-}$. The $\mathrm{NH}_{3}$ solution was dropped into the final 94 mixture to adjust the $\mathrm{pH}$ to $6-6.5$. The final mixture was stirred for $30 \mathrm{~min}$ at $60-80{ }^{\circ} \mathrm{C}$ to form the 95 sol. The sol was transferred to the autoclave at $180{ }^{\circ} \mathrm{C}$ for $12 \mathrm{~h}$. The precipitation was collected by 96 filtering, washing, and drying at $95^{\circ} \mathrm{C}$ for $24 \mathrm{~h}$. 
99 The X-ray diffraction spectra were recorded on a D5005-SIEMENS diffractometer with $\mathrm{Cu}-\mathrm{K} \alpha$

100 radiation $(\lambda=1.54056 \AA)$. The synthesized olivines were observed using a Hitachi FE-SEM S-4800

101 field-emission scanning electron microscope coupled with an Oxford 300 EDX analysis system. The 102 micro-Raman spectra were recorded on a LABRAM-1B spectrophotometer (Jobin Yvon, France). The 103 electrochemical properties of the synthesized olivines were evaluated by cyclic voltammetry (CV) at 104 a scan rate of $1 \mathrm{mV} \mathrm{s}^{-1}$, galvanostatic charge/discharge tests, and electrochemical impedance 105 spectroscopy by using a VMP3 apparatus (BioLogic, France) in the frequency range $5 \mathrm{mHz}$ to $105 \mathrm{~Hz}$ 106 and $10 \mathrm{mV}$ peak-to-peak excitation signal.

\section{Devices preparation}

109 The synthesized olivine powders were mixed with carbon black as a conductive agent, polyvinylidene 110 fluoride (PVDF) as binder in the ratio of 90:5:5, respectively, in a porcelain mortar and pestle. The 111 prepared mixtures were coated onto a $0.1 \mathrm{~mm}$ aluminium sheet, dried at $120^{\circ} \mathrm{C}$ in an oven for $12 \mathrm{~h}$, 112 and pressed on a press machine to create a thickness of $20 \square \mathrm{m}$. The electrodes were then formed to 113 circular plates with a diameter of $1.6 \mathrm{~cm}$ on a stamping machine. Coin-cells CR-2032 were assembled 114 in an argon-filled glove box with an anode of lithium metal. The electrolyte solutions were $1 \mathrm{M} \mathrm{LiPF}_{6}$ 115 in a mixture of ethylene carbonate (EC) and dimethyl carbonate (DMC) at a volumetric ratio of 2:1.

\section{3. Results and discussion}

\section{Structural and morphological characterizations}

118 The XRD spectra of the synthesized olivine samples (Fig. 1A) show a pure and very well crystallized 119 single olivine phase without impurity (e.g., $\mathrm{MnO}_{2}, \mathrm{Li}_{2} \mathrm{O}$, and $\mathrm{Fe}_{2} \mathrm{O}_{3}$ ). All the diffraction peaks were 120 identified in an orthorhombic structure with a space group of $\mathrm{P}_{\mathrm{nma}}$ (JCPDS 81-1173) [14, 20]. In the 121 olivine phase, the atoms are located at $4 \mathrm{a}$ for lithium, $4 \mathrm{c}$ for iron, $4 \mathrm{c}$ for phosphorous, and $4 \mathrm{c}$ and $8 \mathrm{a}$ 
122 for oxygen. The Mn substitute of $\mathrm{Fe}$ is at the $4 \mathrm{c}$ site. The lattice parameters are calculated by the Celref 123 program and detailed in Table $\mathbf{1}$. The lattice expansion of the Mn-doped olivine samples depended on 124 the degree of Mn substitution as well as the larger ionic radius of $\mathrm{Mn}^{2+}\left(\mathrm{rMn}_{2}+=0.08 \mathrm{~nm}>\mathrm{rFe} 2+=0.074\right.$ $125 \mathrm{~nm})[14,20]$

126 The broadening of the diffraction peaks was attributed to the nanocrystallinity of the samples. The average crystalline size is calculated from the full width at half maximum (FWHM) through the DebyeScherrer equation [23]:

$$
d_{h k l}=\frac{k \cdot \lambda}{\beta \cdot \cos \theta}
$$

130 where $\mathrm{d}_{\mathrm{hkl}}$ is the average particle size, $k$ is the constant depending on the crystallite shape (0.9), $\lambda$ is 131 the wavelength of the copper $\mathrm{K}_{\alpha} \mathrm{X}$-ray radiation, $\beta$ is the FWHM of the most intense peak (in rad), 132 and $\theta$ is the diffraction angle. The average estimation of the crystallite size is around $20 \mathrm{~nm}$ for all 133 samples. This sub-micron size could indicate fast kinetics of lithium insertion due to a shortening of 134 the lithium pathway for diffusion.

135 The Raman spectra of the olivine $\mathrm{LiMn}_{0.1} \mathrm{Fe}_{0 .}{ }_{9} \mathrm{PO}_{4}$ at high frequency $750-2000 \mathrm{~cm}^{-1}$ (Fig. 1B) confirms the typical fingerprints of an olivine-type structure as well as the successful carbon coating 137 on surface olivines from the pyrolysis process. Three $A_{g}$ bands $\left(v_{1}, v_{2}\right.$, and $v_{3}$ at $943 \mathrm{~cm}^{-1}, 993 \mathrm{~cm}^{-1}$ 138 and $1065 \mathrm{~cm}^{-1}$, respectively) represented the vibrational modes of the [PO 4$]$ tetrahedron. The mode $v_{2}$ $139\left(993 \mathrm{~cm}^{-1}\right)$ was assigned to symmetric $\mathrm{O}-\mathrm{P}-\mathrm{O}$ bond bending, while the two modes $v_{1}$ and $v_{3}$ were 140 characterized as symmetric and anti-symmetric $\mathrm{P}-\mathrm{O}$ stretching, respectively [30, 31].

141 The SEM image in Fig. 2 shows that the synthesized olivine $\mathrm{LiMn}_{\mathrm{x}} \mathrm{Fe}_{1-\mathrm{x}} \mathrm{PO}_{4}$ samples crystallized with 142 uniform size. The SEM of the original olivine $\mathrm{LiFePO}_{4}$ sample (Fig. 2a) shows $\mathrm{LiFePO}_{4}$ as consisting 143 of spherical-like particles with a narrow particle size distribution in range from $200 \mathrm{~nm}$ to $400 \mathrm{~nm}$. 144 When $\mathrm{Mn}$ is doped into $\mathrm{LiMn}_{\mathrm{x}} \mathrm{Fe}_{1-\mathrm{x}} \mathrm{PO}_{4}$, the particle size strongly reduces and the samples became 145 more porous see Fig. 2b, Fig. 2c, and Fig .2d. It can be seen that particle size decreased with increasing $146 \mathrm{Mn}$. In particular, the particle size of $\mathrm{LiMn}_{0.3} \mathrm{Fe}_{0.7} \mathrm{PO}_{4}$ is around $50 \mathrm{~nm}$ (Fig. 2d). The EDX spectra of 

the three Mn-doped samples (Fig. 3) showed the indicators of $\mathrm{Mn}, \mathrm{Fe}, \mathrm{P}$, and $\mathrm{O}$ and confirmed the stoichiometric relationship between Mn:Fe (Table 2) was similar to the desired composition.

\section{Electrochemical measurements}

151 The CVs of the $\mathrm{LiMn}_{\mathrm{x}} \mathrm{Fe}_{1-\mathrm{x}} \mathrm{PO}_{4}(\mathrm{x}=0,0.1,0.2$, and 0.3$)$ samples at a scan rate of $1 \mathrm{mV} \mathrm{s}^{-1}$ are shown 152 in Fig. 4A. The original olivine $\mathrm{LiFePO}_{4}$ was measured over a voltage range of 3 - $4 \mathrm{~V}$ while the Mn153 doped olivines were scanned at a wider range of $2.5-4.5 \mathrm{~V}$. As can be seen from the CVs, the 154 traditional reversible peak of the $\mathrm{Fe}^{3+} / \mathrm{Fe}^{2+}$ couple at $3.45-3.55 \mathrm{~V}$ appeared in the obtained 155 voltammograms. With a greater degree of Mn substitution, the redox peak in the high voltage region $156(\sim 4 \mathrm{~V})$ becomes more observable. On the other hand, Mn doping into the original olivine can also lead 157 to a slight shift in the Fe-redox potential, which will be discussed further in cycling test section. The 158 Nyquist plots of the EIS for the $\mathrm{LiMn}_{x} \mathrm{Fe}_{1-\mathrm{x}} \mathrm{PO}_{4}(\mathrm{x}=0,0.1,0.2$, and 0.3$)$ samples (Fig. 4B) exhibited 159 three regions: (i) a "quasi" semi-circle in the high-medium frequency corresponding to the charge160 transfer; (ii) a straight line 45 degrees from the real axis in low frequency region (in frequency range 161 from $1 \mathrm{~Hz}-0.1 \mathrm{~Hz})$ demonstrating the Warburg impedance, and (iii) at very low frequencies $\left(f<10^{-3}\right.$ $162 \mathrm{~Hz}$ ) the phase angle is increases due to the finite diffusion process [5, 32]. It is observed that Mn doping 163 is helpful for decreasing charge transfer in olivine, which suggests fast electron transfer as well as 164 stability in cycling performance.

165 The galvanostatic cycling tests at a constant current of $0.1 \mathrm{C}$ in the potential range of $2.5-4.3 \mathrm{~V}$ are 166 shown in Fig. 5A. It is well known that the $\mathrm{LiFePO}_{4}$ profile drops rapidly to plateau at a voltage of $1673.39 \mathrm{~V}$ when discharging and leaps to $3.45 \mathrm{~V}$ when charging. This profile can be considered as a two168 phase mechanism between the $\mathrm{LiFePO}_{4}$ phase and $\mathrm{FePO}_{4}$ phase (Fig. 5A, curve a). However, the $\mathrm{Mn}$ 169 substitution in olivine leads a significant change in the cycling profile (Fig. 5A, curve b to curve d). 170 The discharge curve of the lowest Mn-doped sample falls slowly with a light bend over $3.7 \mathrm{~V}$ and 171 reaches the main plateau at $3.41 \mathrm{~V}$, while the reverse plateau appears at $3.47 \mathrm{~V}$. It was reasonable that 
172 the Mn-redox signal of $\mathrm{LiMn}_{0.1} \mathrm{Fe}_{0.9} \mathrm{PO}_{4}$ was hardly seen in the obtained voltammogram. In the other

173 Mn-doped samples, the cycling profiles are demonstrated by a well-defined plateau at over $3.45 \mathrm{~V}$ and

174 a short one at around 3.90 V. It was recognized that increasing the degree of Mn doping prolongs the

175 capacity in the high voltage region and shortens it in the lower region. Indeed, the capacity was boosted

176 from $20 \mathrm{mAh} \mathrm{g}^{-1}$ for $\mathrm{LiMn}_{0.2} \mathrm{Fe}_{0.8} \mathrm{PO}_{4}$ to nearly $40 \mathrm{mAh} \mathrm{g}^{-1}$ for $\mathrm{LiMn}_{0.3} \mathrm{Fe}_{0.7} \mathrm{PO}_{4}[20,21]$.

177 On the other hand, it was observed that Mn doping also lead to shifts in the redox potential as well as an expansion of the polarization. Notably, at mid-capacity $\left(\sim 75 \mathrm{mAh} \mathrm{g}^{-1}\right)$, the discharge potential shifted towards $50 \mathrm{mV}$ for the Fe-redox potential (from 3.40 to $3.45 \mathrm{~V}$ ) with an increase in the degree of $\mathrm{Mn}$ doping and the polarization considerably increased from $50 \mathrm{mV}$ (for $\mathrm{LiFePO}_{4}$ ) to $63 \mathrm{mV}$ (for LiMn $\left.0.3 \mathrm{Fe}_{0.7} \mathrm{PO}_{4}\right)$. This finding is consistent with the obtained cyclic voltammograms and can be interpreted as (i) the $\mathrm{Mn}$ is more electropostitive than Fe and (ii) the Mn substitution of Fe can be expected to strengthen the $\mathrm{Fe}-\mathrm{O}$ covalence, which raises the $\mathrm{Fe}^{2+} / \mathrm{Fe}^{3+}$ redox energy and shifts the redox voltage of the $\mathrm{Fe}^{2+} / \mathrm{Fe}^{3+}$ couple higher [33].

The cycling performance of the olivines are presented in Fig. 5B. The initial capacity of $\mathrm{LiFePO}_{4}$ reached $169 \mathrm{mAh} \mathrm{g}^{-1}$, which was close to the theoretical capacity, however $10 \%$ of the initial capacity was lost after 50 cycles with a final capacity of $152 \mathrm{mAh} \mathrm{g}^{-1}$. For the Mn-doped olivines, $\mathrm{LiMn}_{\mathrm{x}} \mathrm{Fe}_{1}$ ${ }_{x} \mathrm{PO}_{4}(\mathrm{x}=0.1,0.2$, and 0.3$)$, there was negligible capacity loss and their final capacity reached 151,

189147 , and $157 \mathrm{mAh} \mathrm{g}^{-1}$, respectively. The capacity loss can be interpreted by the release of Mn during 190 the charge-discharge process. The Coulombic retentions were over 95\% during the cycling test, which 191 indicated a reversible Li-intercalation into the olivine hosts.

192 The apparent chemical coefficient of diffusion of lithium ( $\mathrm{DLi}_{\mathrm{Li}}$ ) is a key parameter that evaluates the 193 lithium transport into the intercalation hosts, which can be determined by the galvanostatic intermittent 194 titration technique (GITT). This method imposes a constant current through the cell for a certain time 195 interval $[34,35]$. The open circuit voltage (OCV) curve was measured with a constant discharge rate 196 of $\mathrm{C} / 50$ for $30 \mathrm{~min}$ followed by an OCV relaxation period of $5 \mathrm{~h}$ to the equilibrium voltage. The 
diffusion process within the host was assumed to obey Fick's second law of diffusion, and under 198 galvanostatic conditions, it obeys the following Eq. 2:

$D=\frac{4}{\pi}\left(\frac{V_{M}}{S . F . z_{A}}\right)^{2}\left[I_{0} \cdot\left(\frac{d E}{d x}\right) /\left(\frac{d E}{d \sqrt{t}}\right)\right]^{2}$

200 where $\mathrm{V}_{\mathrm{M}}$ is the molar volume of the host, $\mathrm{S}$ is the active surface of the electrode, F is Faraday's 201 constant $\left(\mathrm{F}=96500 \mathrm{C} \mathrm{mol}^{-1}\right), \mathrm{zA}_{\mathrm{A}}$ is the charge of the mobile species ( $\left.\mathrm{ZLi}_{\mathrm{Li}}=1\right)$, $\mathrm{I}_{\mathrm{o}}$ is the magnitude of 202 the current pulse, $\mathrm{dE} / \mathrm{dx}$ is the slope of the OCV curve, and $\mathrm{dE} / \mathrm{dt}^{1 / 2}$ was directly obtained from the measurement of the voltage as a function of time during the constant current flux. The olivine intercalates the Li ions in a domino-cascade mechanism that is a transition between the two phases $\mathrm{LiFePO}_{4}$ and $\mathrm{FePO}_{4}[36,37]$. Thus, the galvanostatic curve can be divided in three segments: (i) a quickly dropping voltage as a solid solution segment for Li content below 0.1, (ii) a phase transition segment with Li content ranging from 0.1 to 0.9 , and (iii) other solid solution segments for Li content below 1 . The $\mathrm{D}_{\mathrm{Li}}$ in the sold solution segment is usually more rapid than those in the phase transition region due to the slope $\mathrm{dE} / \mathrm{dx}$. Indeed, the phase transition is characterized by a flat voltage that leads to a small $\mathrm{dE} / \mathrm{dx}$. Figure 6 demonstrates the evolution of $\mathrm{D}_{\mathrm{Li}}$ as a function of lithium content in the

211 olivines. It is observed that the synthesized olivines have a $D_{\mathrm{Li}}$ in the range of $10^{-17}-10^{-15} \mathrm{~cm}^{2} \mathrm{~s}^{-1}$ at 212 the phase transition with $\mathrm{Li}$ content ranging from 0.2 to 0.8 for $\mathrm{LiFePO}_{4}$ and $\mathrm{LiMn}_{0.1} \mathrm{Fe}_{0.9} \mathrm{PO}_{4}$ and 213 from 0.35 to 0.8 for the two other olivines. Moreover, the evolution of $\mathrm{D}_{\mathrm{Li}}$ in $\mathrm{LiMn}_{0 .} \mathrm{Fe}_{0.8} \mathrm{PO}_{4}$ and 214 LiMn0.3Fe0.7 $\mathrm{PO}_{4}$ shows a peak at $\mathrm{XLi}=0.1$ due to a short plateau of the redox couple $\mathrm{Mn}^{2+} / \mathrm{Mn}^{3+}$, which 215 is consistent with the galvanostatic curve. Except at the phase transition, the $\mathrm{D}_{\mathrm{Li}}$ of the Mn-doped 216 olivines were significantly higher than the original olivine, which can be explained by enlarged lattice 217 due to Mn substitution as well as a 1D channel in the (010) plane that is favourable for Li transport. 218 Briefly, the $\mathrm{D}_{\mathrm{Li}}$ values in our results are comparable to previous reports which were determined by 219 other electrochemical methods (EIS, GITT) [22, 24, 38, 39]. 
222 The olivine $\mathrm{LiMn}_{x} \mathrm{Fe}_{1-\mathrm{x}} \mathrm{PO}_{4}(\mathrm{x}=0,0.1,0.2$, and 0.3$)$ were successfully synthesized via the

223 hydrothermal route and presented an orthorhombic structure with lattice parameters that agreed with 224 prior reports. The electrochemical results showed that the original $\mathrm{LiFePO}_{4}$ lost $10 \%$ of its initial 225 capacity after 50 cycles with a remaining capacity of $152 \mathrm{mAh} \mathrm{g}^{-1}$. For the Mn-doped olivine samples, 226 there was negligible capacity loss and they reached 151, 147, and $157 \mathrm{mAh} \mathrm{g}^{-1}$ capacity, respectively.

227 The EIS revealed a rapid charge-transfer with Mn doping and the DLi value from GITT showed a 228 minimum in the two-phase transition segment range of $10^{-17}-10^{-15} \mathrm{~cm}^{2} \mathrm{~s}^{-1}$. The olivine $\mathrm{LiMn}_{\mathrm{x}} \mathrm{Fe}_{1}$ $229{ }_{x} \mathrm{PO}_{4}$, therefore, can lead to the development of high-performance lithium-ion batteries.

\section{Author contribution statement}

231 Dung V. Trinh: Investigation.

232 Mai T. T. Nguyen : : Investigation.

233 Hue T. M. Dang : : Investigation, Dung T. Dang : Data curation.

234 Hang T. T. Le : Formal analysis.

235 Huynh T. N. Le : Formal analysis.

236 Hoang V. Tran : Writing - review \& editing.

237 Chinh D. Huynh : Supervision, Writing - review \& editing.

238 Declaration of Conflict of Interest

239 The authors declare that they have no known competing financial interests or personal relationships 240 that could have appeared to influence the work reported in this paper.

\section{Acknowledgments}

242 We acknowledge the Energy Storage Materials Lab in Dankook University (Chungnam, Republic of 243 Korea) for the help with electrochemical measurements. This research was funded by Vietnam 
244 National Foundation for Science and Technology Development (NAFOSTED) under grant number $245 \quad 104.03-2017.349$.

\section{References}

247 [1] R. El khalfaouy, H. El knidri, R. Belaabed, A. Addaou, A. Laajeb, A. Lahsini, Synthesis and 248 characterization of LiMnPO4 material as cathode for Li-ion batteries by a precipitation method 249 and solid-state blending, Journal of Materials and Environmental Science, 7 (2016) 40-49.

250 [2] P. R. Kumar, M. Venkateswarlu, N. Satyanarayana, Three-dimensional lithium manganese 251 phosphate microflowers for lithium-ion battery applications, Journal of Applied Electrochemistry $42(2012)$ 163-167.

[3] F. Zhou, K. Kang, T. Maxisch, G. Ceder, D. Morgan, The electronic structure and band gap of LiFePO4 and LiMnPO4, Solid State Communications, 132 (2004) 181-186.

[4] A. Nazir, Hang T. T. Le, A. Kasbe, C.-Jin Park, Si nanoparticles confined within a conductive 2D porous $\mathrm{Cu}$-based metal-organic framework $(\mathrm{Cu} 3(\mathrm{HITP}) 2)$ as potential anodes for high-capacity Li-ion batteries, Chemical Engineering Journal, 405 (2021) Article number 126963.

[5] N. H. Vu, H. T.T. Le, V. H. Hoang, V.-D. Dao, H. T. Huu, Y.-S. Jun, W. B. Im, Highly N-doped, H-containing mesoporous carbon with modulated physicochemical properties as high-performance anode materials for Li-ion and Na-ion batteries, Journal of Alloys and Compounds, 851 (2021) Article number 156881.

[6] S.-Y. Chung, J. T. Bloking, Y.-M. Chiang, Electronically conductive phospho-olivines as lithium storage electrodes, Nature Materials, 1 (2002) 123-128.

[7] A. K. Padhi, K. S. Nanjundaswamy, J. B. Goodenough, Phospho-olivines as Positive-Electrode Materials for Rechargeable Lithium Batteries, Journal of The Electrochemical Society, 144 (1997) $1188-1194$. 
[8] L. Liang, J. Jiang, F. Jiang, G. Hu, Y. Cao, Z. Peng, K. Du, An ordered olivine-type LiCoPO4 layer grown on LiNi0.6Mn0.2Co0.2O2 cathode materials applied to lithium-ion batteries, Journal of Alloys and Compounds, 695 (2017) 1993-1997.

[9] L. Wang, Y. Li, J. Wu, F. Liang, K. Zhang, R. Xu, H. Wan, Y. Dai, Y. Yao, Synthesis mechanism and characterization of $\mathrm{LiMn} 0.5 \mathrm{Fe} 0.5 \mathrm{PO} 4 / \mathrm{C}$ composite cathode material for lithium-ion batteries,

[10] Z. Deng, Q. Wang, D. Peng, H. Liu, Y. Chen, Fast precipitation-induced LiFe0.5Mn0.5PO4/C nanorods with a fine size and large exposure of the (010) faces for high-performance lithium-ion batteries, Journal of Alloys and Compounds, 794 (2019) 178-185.

[11] L. Bao, G. Xu, J. Wang, H. Zong, L. Li, R. Zhao, S. Zhou, G. Shen, G. Han, Hydrothermal synthesis of flower-like LiMnPO4 nanostructures self-assembled with (010) nanosheets and their application in Li-ion batteries, CrystEngComm, 17 (2015) 6399-6405

[12] M. Gaberscek, R. Dominko, J. Jamnik, Is small particle size more important than carbon coating? An example study on LiFePO4 cathodes, Electrochemistry Communications, 9 (2007) 2778-2783.

[13] L.L. M. Winkowska, T. Strachowski, M. Wasiucionek, Optimization of synthesis of single phase nanostructured LiFePO4 materials, MATERIAŁY ELEKTRONICZNE (Electronic Materials), 44 (2016) 4-8.

[14] D. Yan, Y. Zhao, Y. Dong, Z. Liang, X. Lin, Synthesis, characterization, and electrochemical properties of Li2Mn1-x Fe x (PO3)4 cathode material for lithium-ion batteries, Journal of Solid State Electrochemistry, 20 (2016) 337-344.

[15] J. Hu, J. Xie, X. Zhao, H. Yu, X. Zhou, G. Cao, J. Tu, Doping Effects on Electronic Conductivity and Electrochemical Performance of LiFePO4, Journal of Materials Science \& Technology, 25 (2009) 405-409. 
290 [16] C. Wang, J. Hong, Ionic/Electronic Conducting Characteristics of LiFePO4 Cathode Materials: 291 The Determining Factors for High Rate Performance, Electrochemical and Solid State Letters, 10 (2007) A65-A69.

[17] P. P. Prosini, M. Lisi, D. Zane, M. Pasquali, Determination of the chemical diffusion coefficient 294 of lithium in LiFePO4, Solid State Ionics, 148 (2002) 45-51.

295 [18] C.-C. Yang, Y.-T. Hsu, C. Karuppiah, J.-Y. Shih, Y.-S. Wu, Z.-H. Wu, S. J. Lue, Synthesis and characterization of $\mathrm{LiFe} 0.5 \mathrm{Mn} 0.3 \mathrm{Co} 0.2 \mathrm{PO} 4 / \mathrm{C}$ composite material for high-voltage Li-ion battery application, Journal of Alloys and Compounds, 750 (2018) 945-958.

[19] D. Fujimoto, Y. Lei, Z.-H. Huang, F. Kang, J. Kawamura, Synthesis and Electrochemical Performance of LiMnPO4 by Hydrothermal Method, International Journal of Electrochemi, Volume 2014 (2014) Article ID 768912.

[20] J. Hong, F. Wang, X. Wang, J. Graetz, LiFexMn1-xPO4: A cathode for lithium-ion batteries, Journal of Power Sources, 196 (2011) 3659-3663.

[21] N. V. Kosova, O. A. Podgornova, A. K. Gutakovskii, Different electrochemical responses of $\mathrm{LiFe} 0.5 \mathrm{Mn} 0.5 \mathrm{PO} 4$ prepared by mechanochemical and solvothermal methods, Journal of Alloys and Compounds, 742 (2018) 454-465.

[22] A. Kumar, R. Thomas, N. K. Karan, J. J. Saavedra-Arias, M. K. Singh, S. B. Majumder, M. S. Tomar, R. S. Katiyar, Structural and Electrochemical Characterization of Pure and Nanocomposite C- Cathodes for Lithium Ion Rechargeable Batteries, Journal of Nanotechnology, Volume 2009 (2009) Article ID 176517

[23] X. Qin, X. Wang, H. Xiang, J. Xie, J. Li, Y. Zhou, Mechanism for Hydrothermal Synthesis of LiFePO4 Platelets as Cathode Material for Lithium-Ion Batteries, Journal of Physical Chemistry C, 114 (2010) 16806-16812.

[24] K. Tang, X. Yu, J. Sun, H. Li, X. Huang, Kinetic analysis on LiFePO4 thin films by CV, GITT, and EIS, Electrochimica Acta, 56 (2011) 4869-4875. 
[25] T.-C. Chen, R.-H. Lin, Effects of Metal Doping on Properties of LiFePO4 Cathode Material by First-Principle Calculation, International Journal of Materials Engineering, 5 (2015) 121-124.

[26] A. Yamada, S. C. Chung, K. Hinokuma, Optimized LiFePO4 for Lithium Battery Cathodes, Journal of The Electrochemical Society, 148 (2001) A224-A229.

[28] S. Yang, P. Y. Zavalij, M. S. Whittingham, Hydrothermal synthesis of lithium iron phosphate

[29] J. Chen, M. S. Whittingham, Hydrothermal synthesis of lithium iron phosphate, Electrochemistry Communications, 8 (2006) 855-858.

[30] M. M. Doeff, J. D. Wilcox, R. Kostecki, G. Lau, Optimization of carbon coatings on LiFePO4, Journal of Power Sources, 163 (2006) 180-184.

[31] M. M. Doeff, Y. Hu, F. McLarnon, R. Kostecki, Effect of Surface Carbon Structure on the Electrochemical Performance of LiFePO4 Electrochemical and Solid State Letters, 6 (2003) A207-A209.

[32] C. Ho, I. D. Raistrick, R. A. Huggins, Application of A-C Techniques to the Study of Lithium Diffusion in Tungsten Trioxide Thin Films, Journal of The Electrochemical Society, 127 (1980) $343-350$.

[33] T. Muraliganth, A. Manthiram, Understanding the Shifts in the Redox Potentials of Olivine LiM1-yMyPO4 (M = Fe, Mn, Co, and Mg) Solid Solution Cathodes, Journal of Physical Chemistry C, 114 (2010) 15530-15540.

[34] W. Weppner, R. A. Huggins, Electrochemical investigation of the chemical diffusion, partial ionic conductivities, and other kinetic parameters in Li3Sb and Li3Bi, Journal of Solid State Chemistry, 22 (1977) 297-308. 
339 [35] C. J. Wen, B. A. Boukamp, R. A. Huggins, W. Weppner, Thermodynamic and Mass Transport $340 \quad$ Properties of " LiAl ", Journal of The Electrochemical Society, 126 (1979) 2258-2266.

341 [36] J. L. Allen, T. R. Jow, J. Wolfenstine, Analysis of the FePO4 to LiFePO4 phase transition, Journal 342 of Solid State Electrochemistry, 12 (2008) 1031-1033.

343 [37] D. Li, H. Zhou, Two-phase transition of Li-intercalation compounds in Li-ion batterie, Materials $344 \quad$ Today, 17 (2014) 451-463.

345 [38] Y. Chen, L. Wang, T. Anwar, Y. Zhao, N. Piao, X. He, Q. Zhu, Application of Galvanostatic 346 Intermittent Titration Technique to Investigate Phase Transformation of LiFePO4 Nanoparticles, 347 Electrochimica Acta, 241 (2017) 132-140.

348 [39] Y. Zhu, C. Wang, Galvanostatic Intermittent Titration Technique for Phase-Transformation 349 Electrodes, Journal of Physical Chemistry C 114 (2010) 2830-2841. 
List of Figures

Figure 1. (A) X-ray diffraction patterns of olivine samples: (a) $\mathrm{LiFePO}_{4}$; (b) $\mathrm{LiMn} 0.1 \mathrm{Fe} 0 .{ }_{9} \mathrm{PO}_{4}$;

(c) $\mathrm{LiMn}_{0.2} \mathrm{Fe}_{0 .} \mathrm{PO}_{4}$ and (d) $\mathrm{LiMn}_{0.3} \mathrm{Fe}_{0.7} \mathrm{PO}_{4}$;

(B) Raman spectra of $\mathrm{LiMn}_{0.1} \mathrm{Fe}_{0.9} \mathrm{PO}_{4}$ sample.

Figure 2. SEM images of synthesized olivine samples:

(a) $\mathrm{LiFePO}$

(b) $\mathrm{LiMn}_{0.1} \mathrm{Fe}_{0.9} \mathrm{PO}_{4}$

(c) $\mathrm{LiMn}_{0.2} \mathrm{Fe}_{0.8} \mathrm{PO}_{4}$ and (d) $\mathrm{LiMn}_{0.3} \mathrm{Fe}_{0.7} \mathrm{PO}_{4}$.

Figure 3. EDS spectra of Mn-doped olivine samples (a) $\mathrm{LiMn}_{0.1} \mathrm{Fe}_{0 .} \mathrm{PO}_{4}$; (b) $\mathrm{LiMn}_{0.2} \mathrm{Fe}_{0.8} \mathrm{PO}_{4}$ and (c) $\mathrm{LiMn}_{0.3} \mathrm{Fe}_{0.7} \mathrm{PO}_{4}$.

Figure 4. (A) Cyclic voltammograms at a scan rate of $5 \mathrm{mV} \mathrm{s}^{-1}$ and (B) corresponding Nyquist plots of electrochemical impedance spectroscopy (EIS) of synthesized olivine samples: (a) $\mathrm{LiFePO}_{4}$; (b)

(d) $\mathrm{LiMn}_{0.3} \mathrm{Fe}_{0.7} \mathrm{PO}_{4}$. Experimental conditions are described in the text.

Figure 5. (A) Typical charge/discharge curves and (B) cycling performance upon 50 cycles of olivine

\section{List of Tables}

Table 1. Lattice parameters of the Mn-doped olivine samples 
Figure 1.

393

394
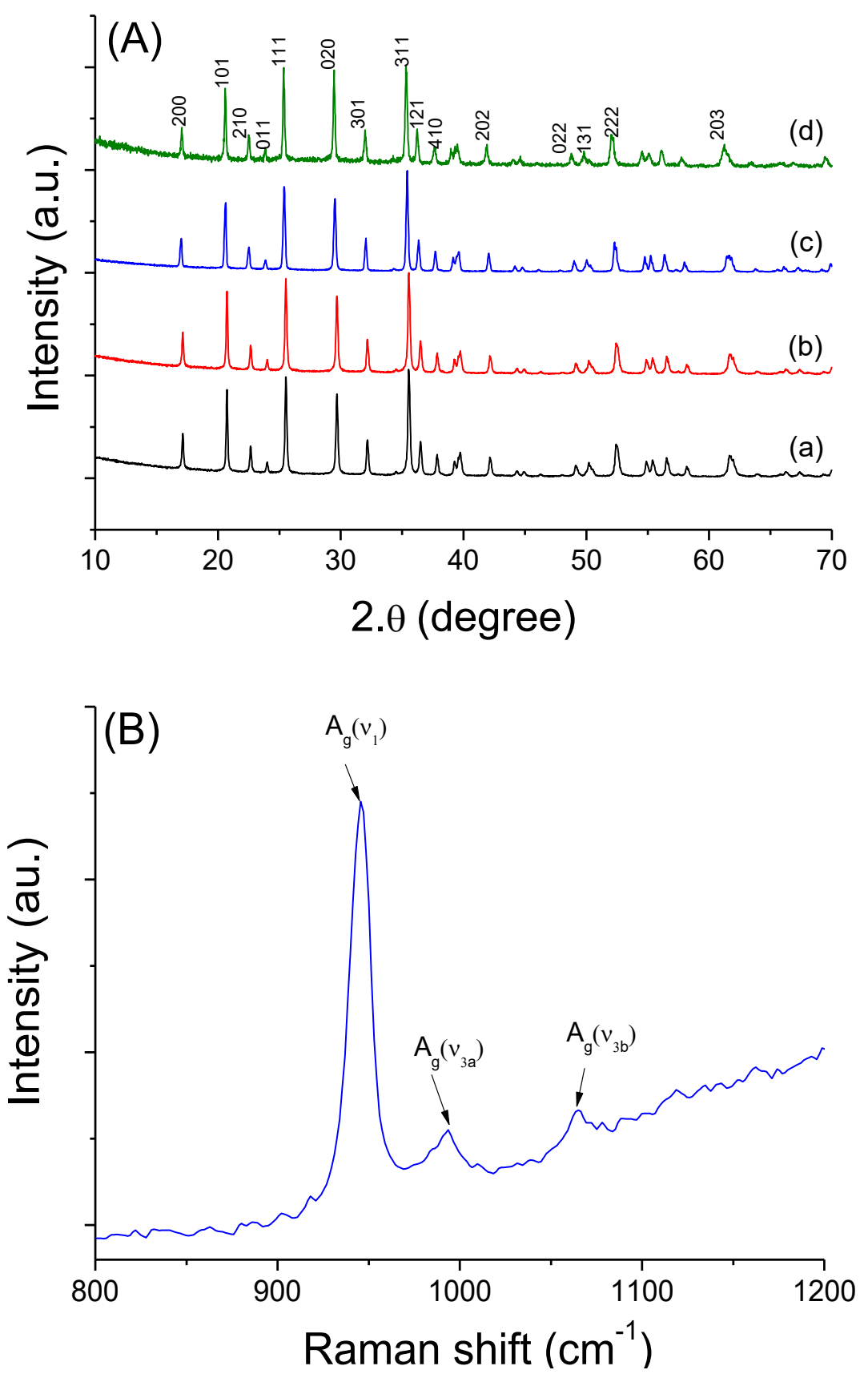

396

397

398

399

400 
402 Figure 2.

403
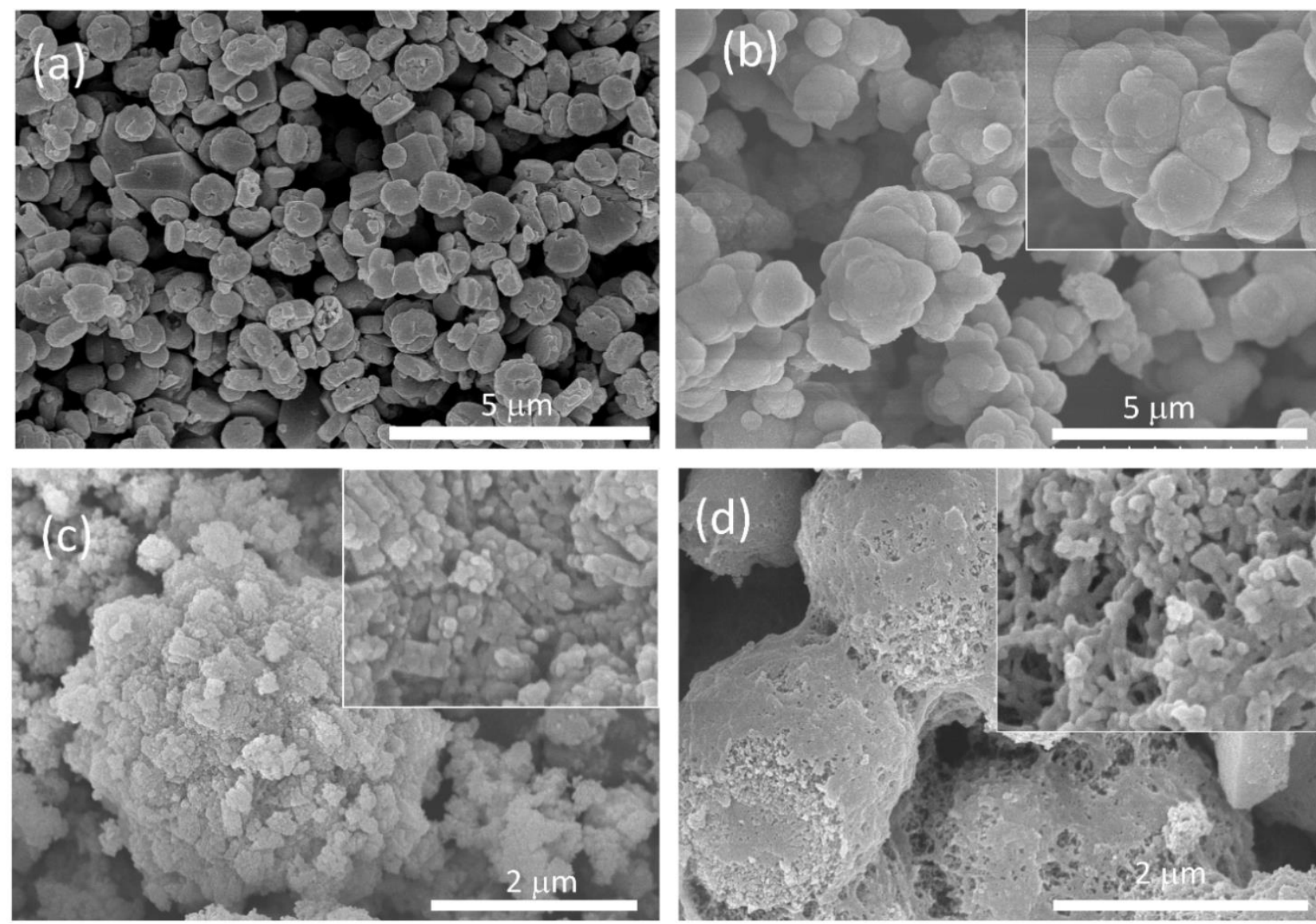

404

405

406

407

408

409

410

411

412

413

414

415

416

417

418 
$420 \quad$ Figure 3.

421

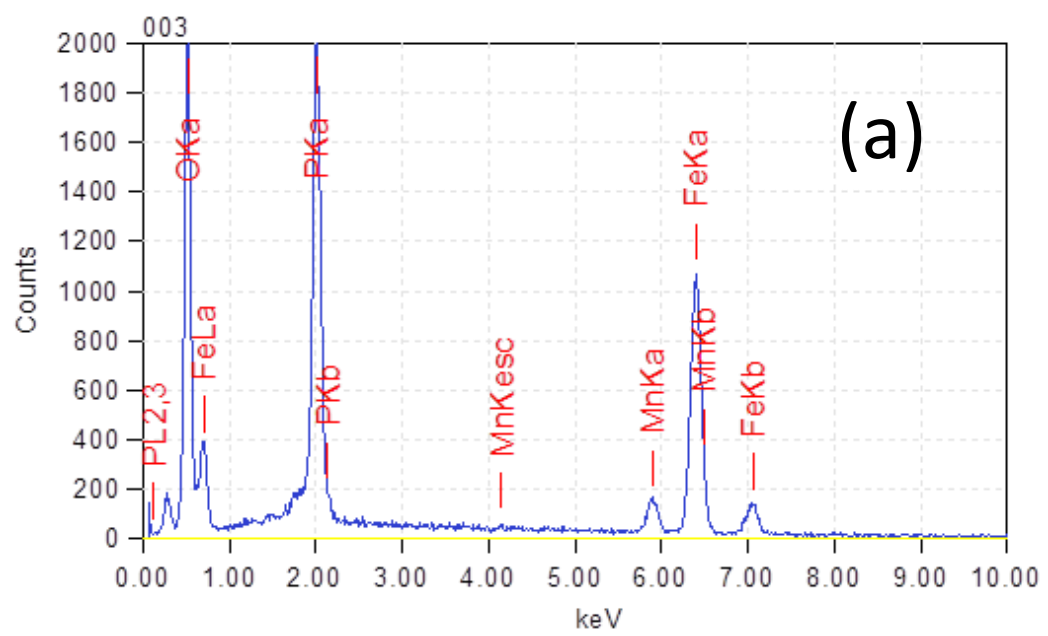

422

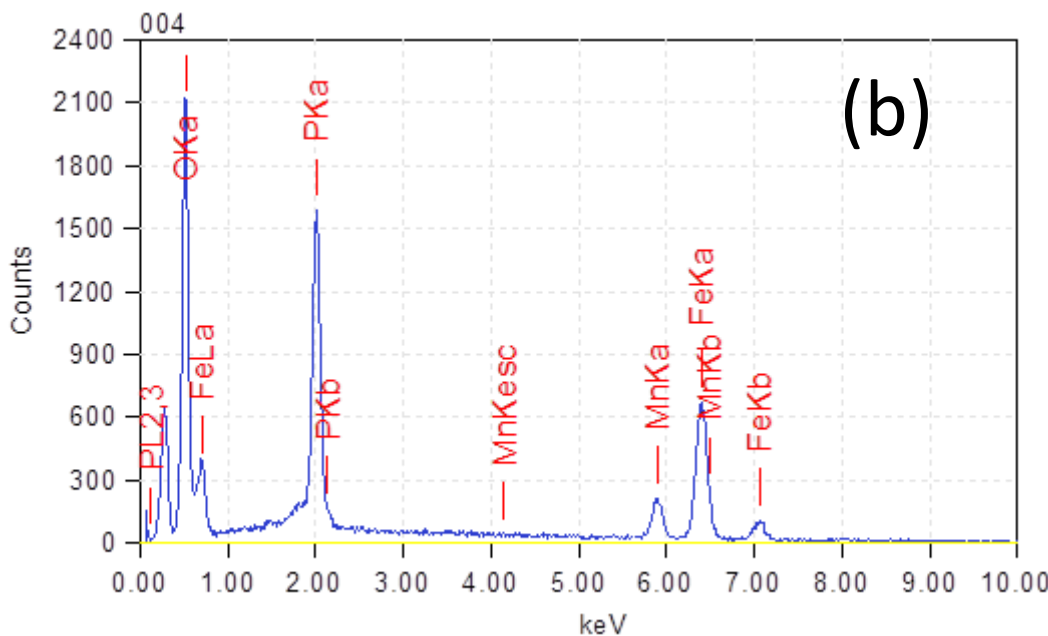

423

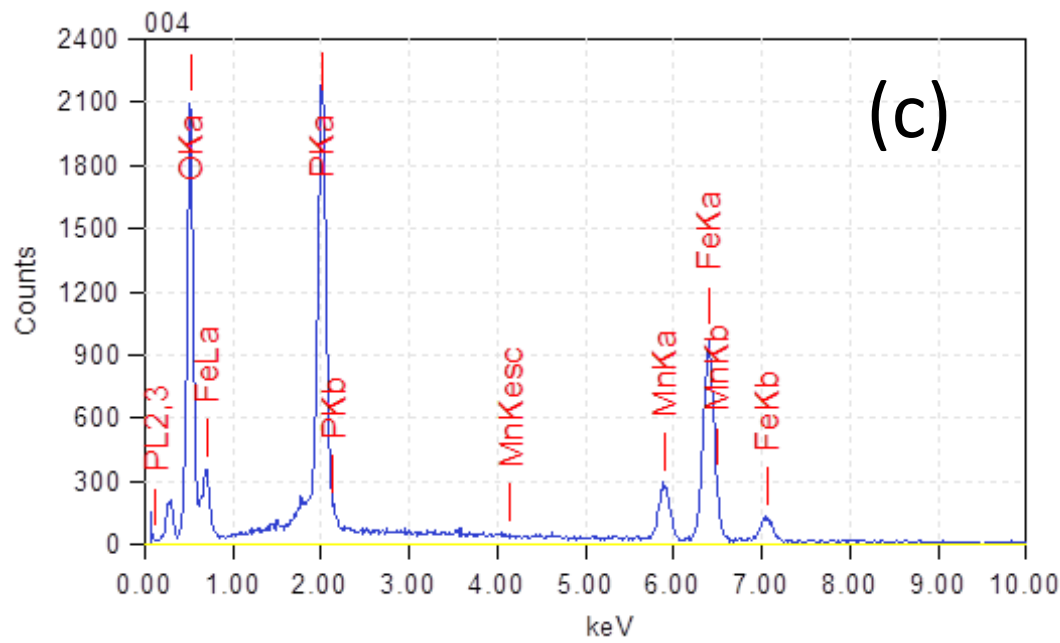


$428 \quad$ Figure 4.

429

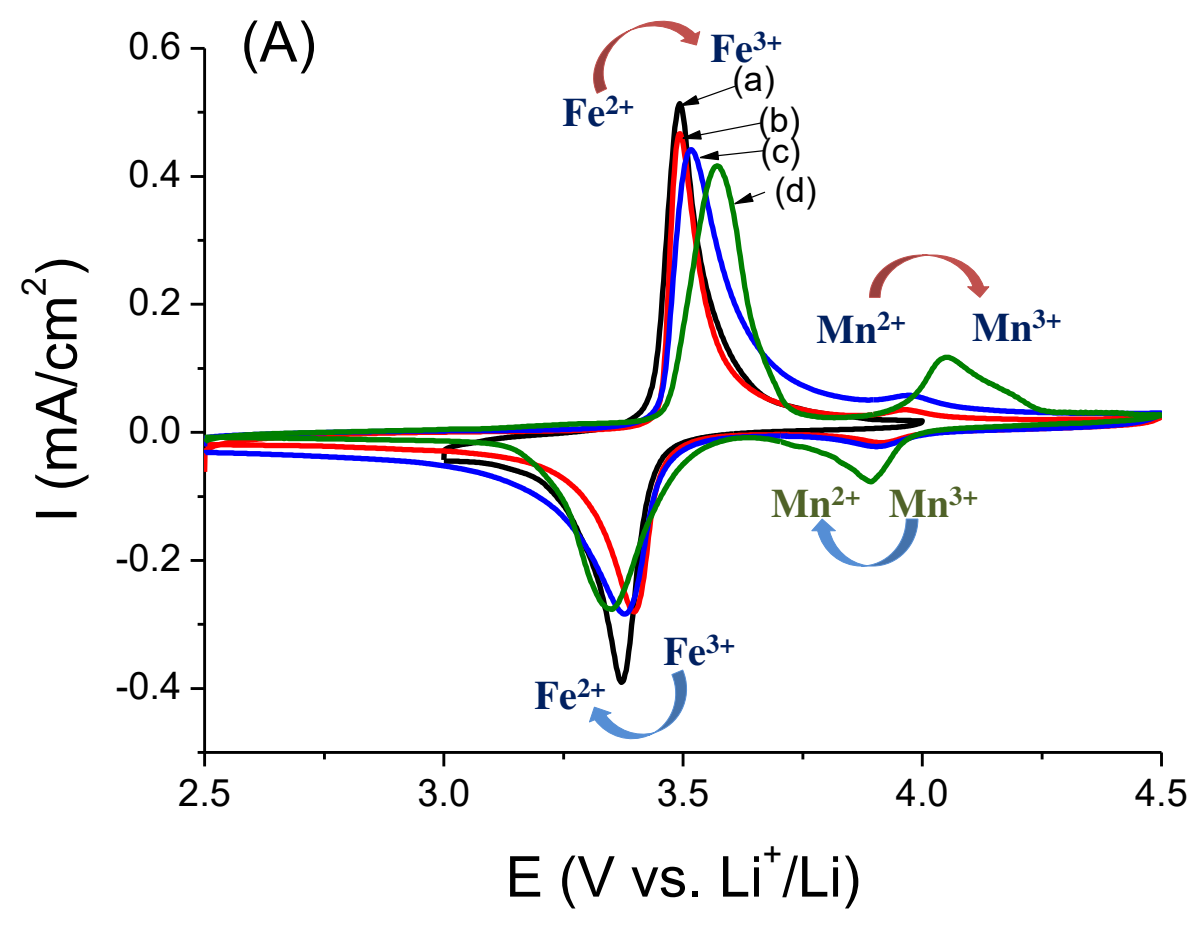

430

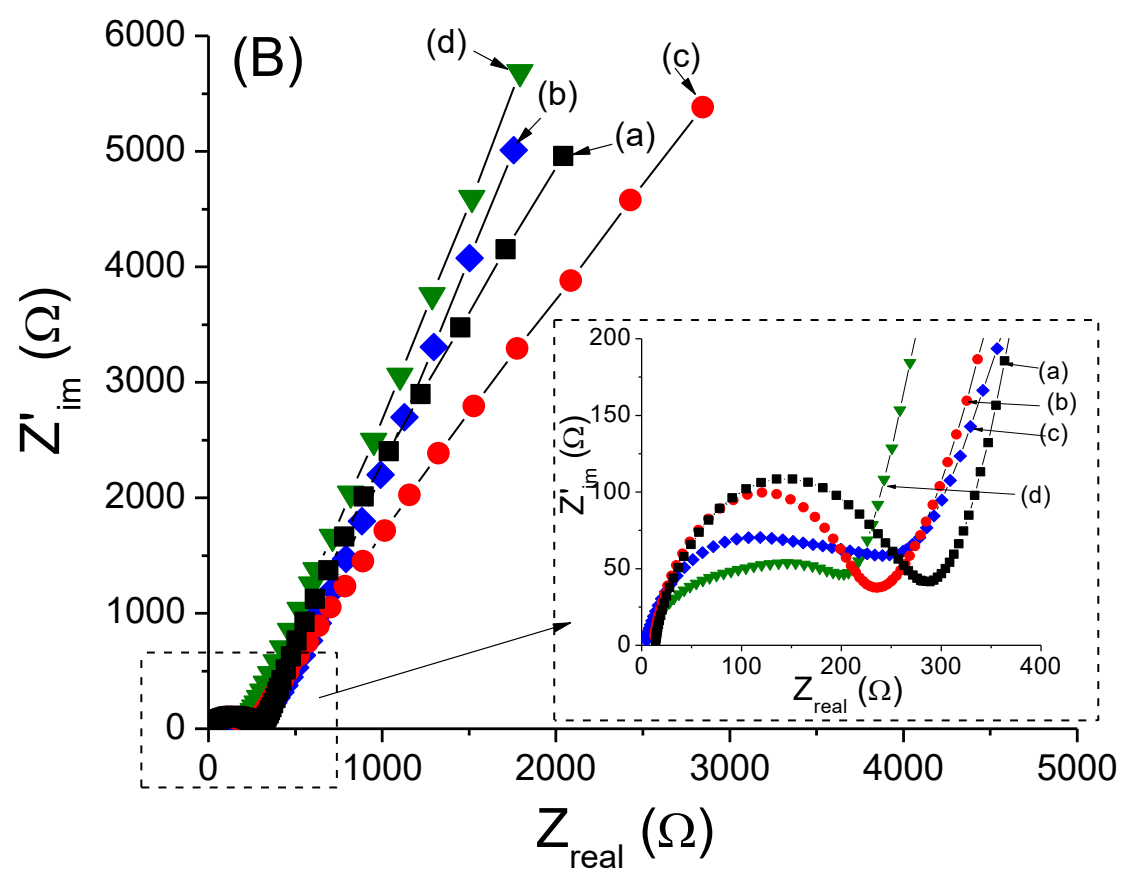


$436 \quad$ Figure 5.

437

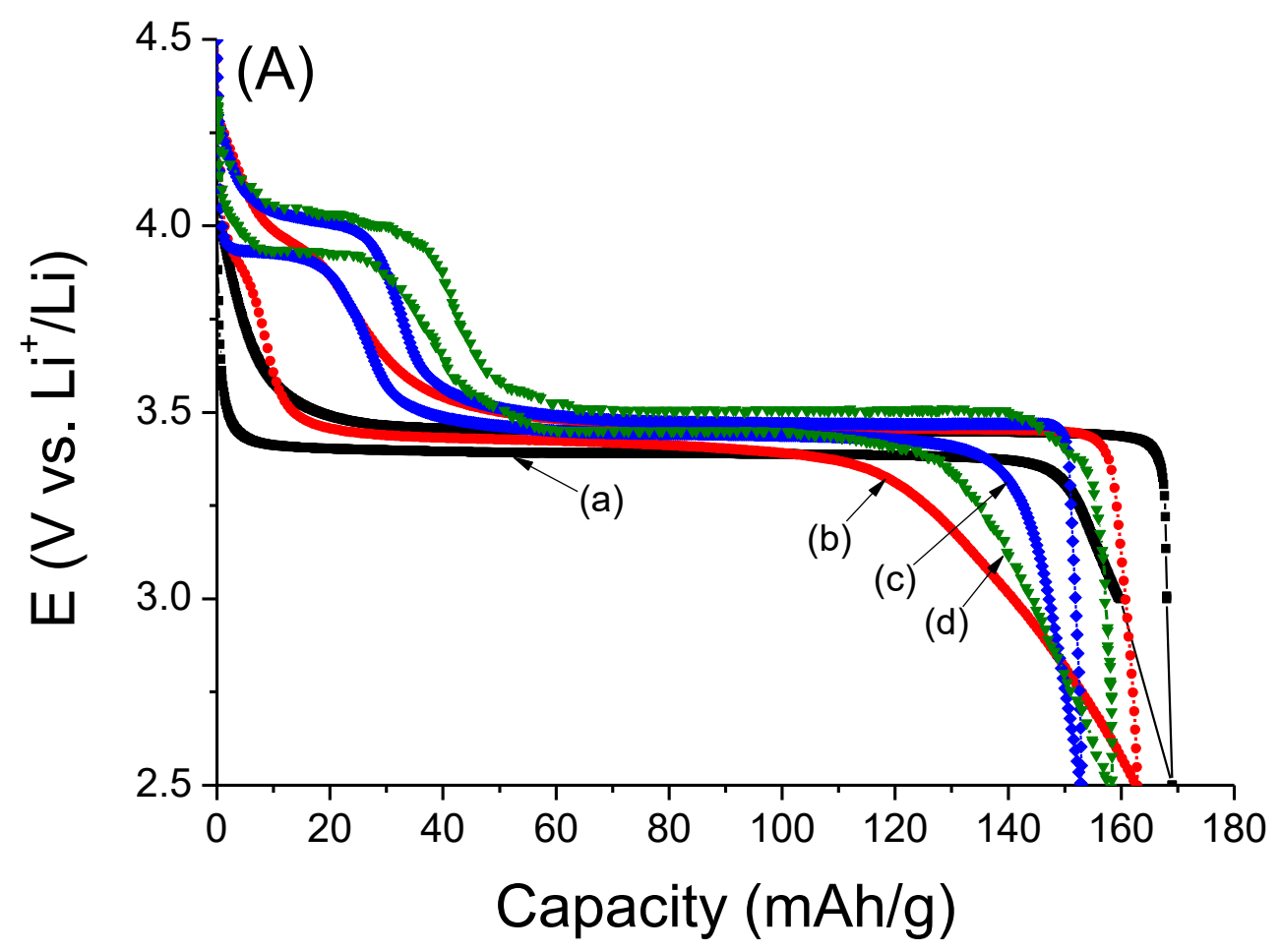

438

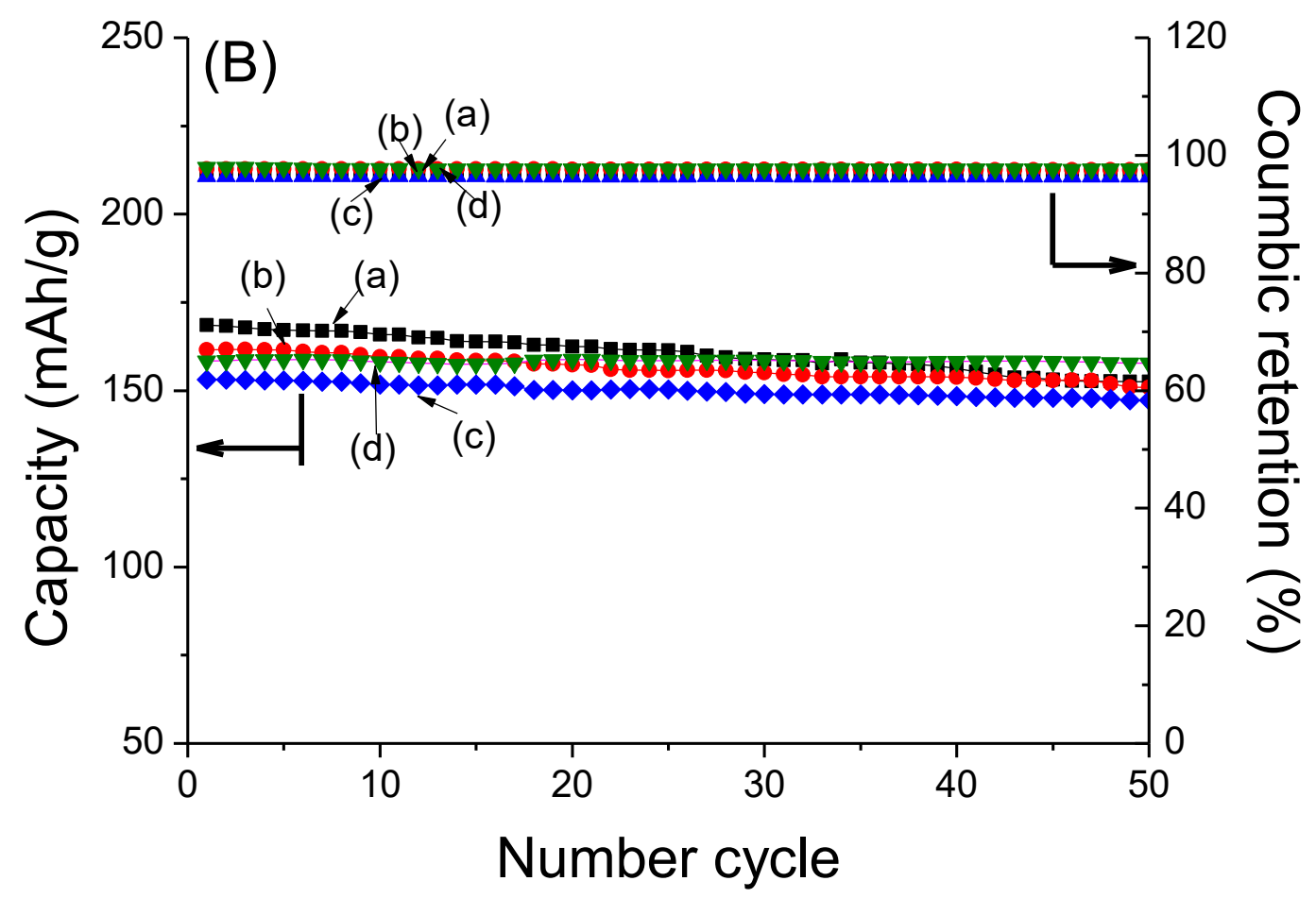


$443 \quad$ Figure 6.

444

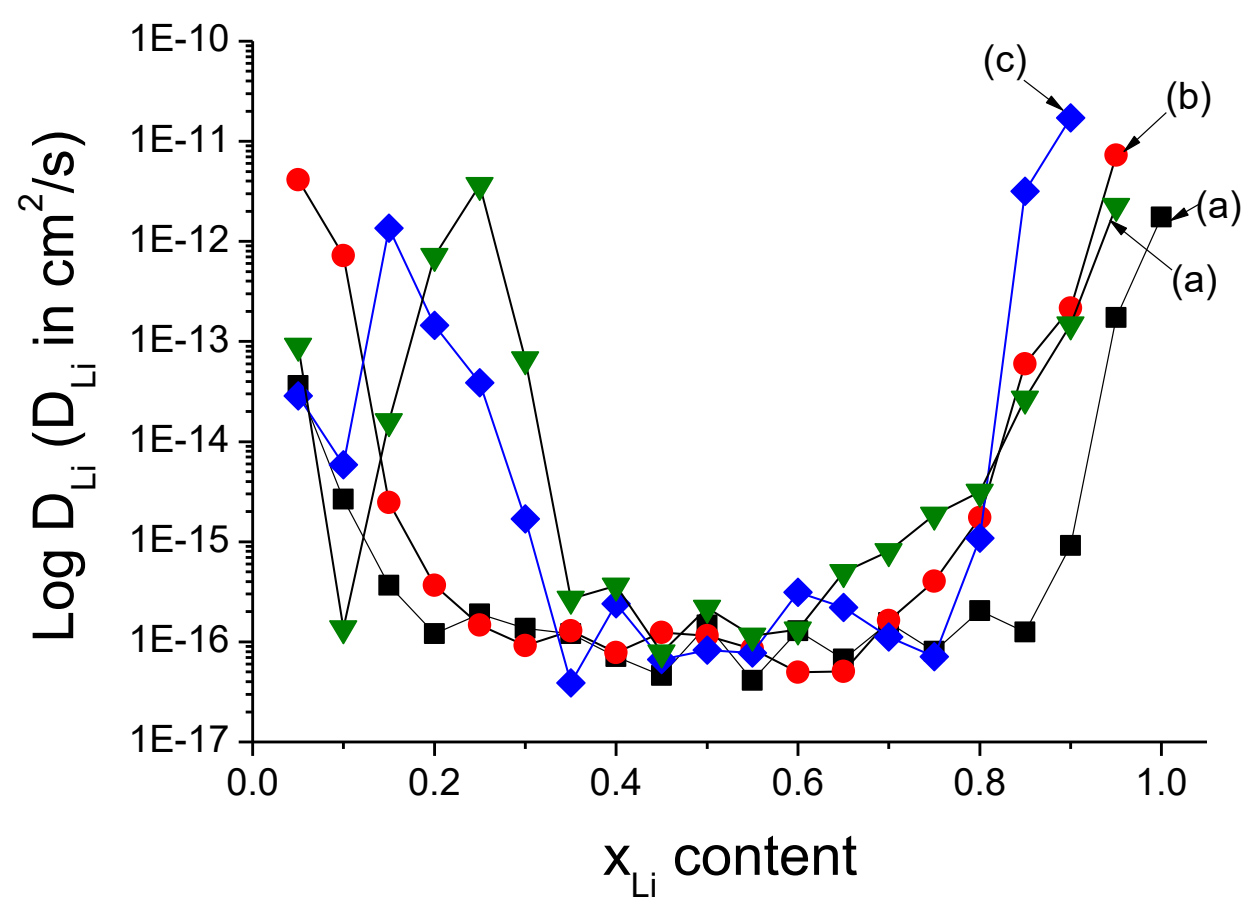


Table 1. Lattice parameters of Mn-doped olivine samples

459

\begin{tabular}{|c|c|c|c|c|c|}
\hline Samples & $\mathbf{a}(\AA)$ & $\mathbf{b}(\AA)$ & c $(\AA)$ & $\mathbf{V}\left(\AA^{\mathbf{3}}\right)$ & $\begin{array}{c}\text { Average crystalline } \\
\text { size }(\mathbf{n m})\end{array}$ \\
\hline $\mathrm{LiFePO}_{4}$ & 10.342 & 6.021 & 4.699 & 292.60 & 19.5 \\
\hline $\mathrm{LiMn}_{0.1} \mathrm{Fe}_{0.9} \mathrm{PO}_{4}$ & 10.330 & 6.012 & 4.702 & 292.01 & 22.5 \\
\hline $\mathrm{LiMn}_{0.2} \mathrm{Fe}_{0.8} \mathrm{PO}_{4}$ & 10.374 & 6.038 & 4.711 & 295.09 & 21.4 \\
\hline $\mathrm{LiMn}_{0.3} \mathrm{Fe}_{0.7} \mathrm{PO}_{4}$ & 10.390 & 6.048 & 4.718 & 296.47 & 21.0 \\
\hline
\end{tabular}

460 
482 Table 2. Elemental composition of Mn-doped olivine samples determined by SEM-EDX 483

\section{LiMno.1Fe $_{0.9} \mathrm{PO}_{4} \quad \mathrm{LiMn}_{0.2} \mathrm{Fe}_{0.8} \mathrm{PO}_{4} \quad \mathrm{LiMn}_{0.3} \mathrm{Fe}_{0.7} \mathrm{PO}_{4}$}

\begin{tabular}{|c|c|c|c|c|c|c|c|}
\hline Elements & $k e V$ & Atom\% & $\mathrm{Mn} / \mathrm{Fe}$ & Atom\% & $M n / F e$ & Atom\% & $M n / F e$ \\
\hline Oxygen & 0.525 & 63.58 & \multirow{4}{*}{$0.12: 0.88$} & 62.34 & & 64.79 & \multirow{4}{*}{$0.26: 0.72$} \\
\hline Phosphorus & 2.013 & 16.11 & & 17.20 & 0.19:0.8 & 14.03 & \\
\hline Manganese & 5.894 & 2.46 & & 3.84 & 1 & 5.55 & \\
\hline Ferrous & 6.398 & 17.85 & & 16.61 & & 15.63 & \\
\hline
\end{tabular}

484

485

486

487

488

489

490

491

492

493

494

495 

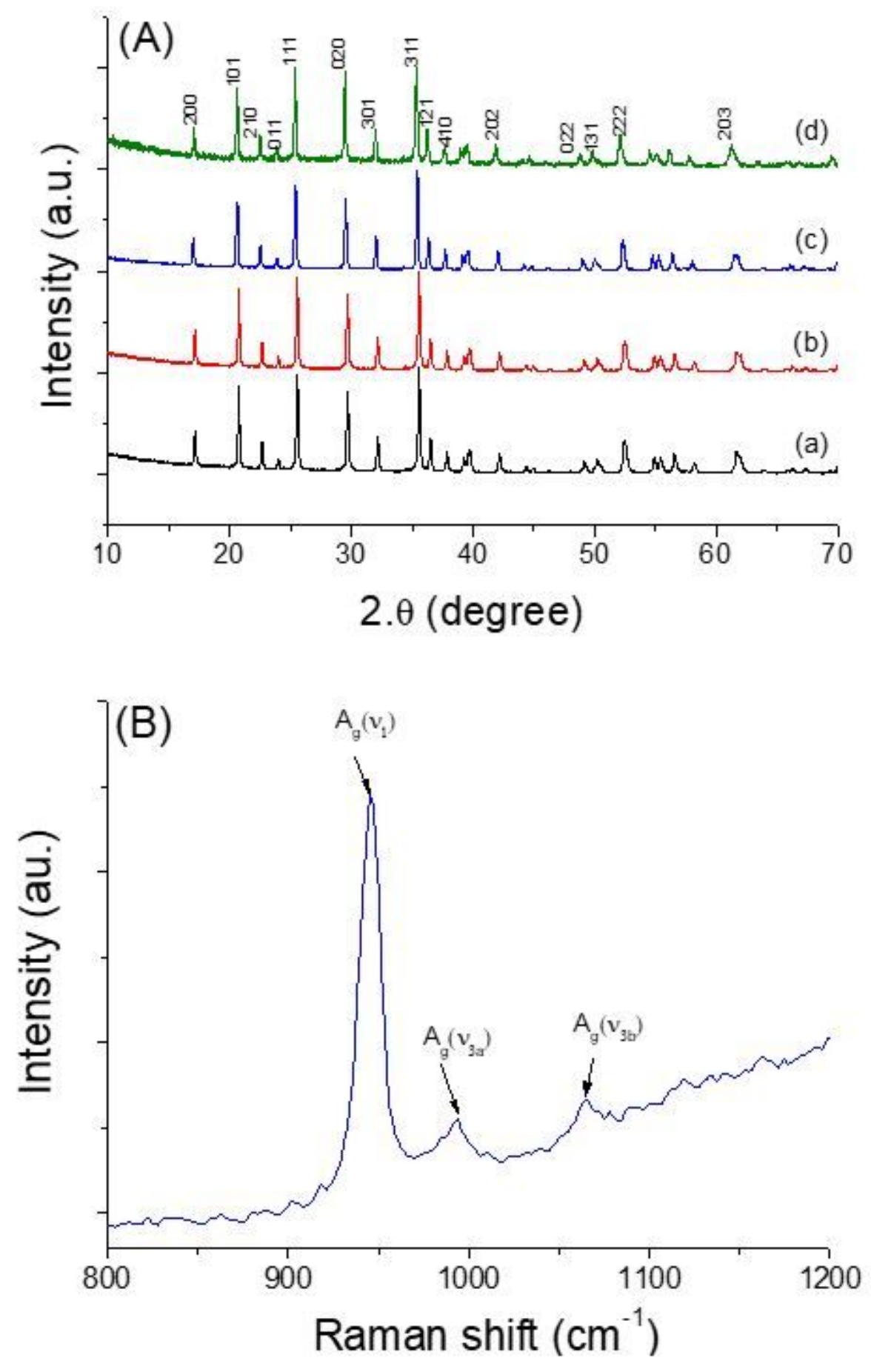

Figure 1

(A) X-ray diffraction patterns of olivine samples: (a) LiFePO4; (b) LiMn0.1Fe0.9PO4; (c) LiMn0.2Fe0.9PO4 and (d) LiMn0.3Fe0.7PO4; (B) Raman spectra of LiMn0.1Fe0.9PO4 sample. 

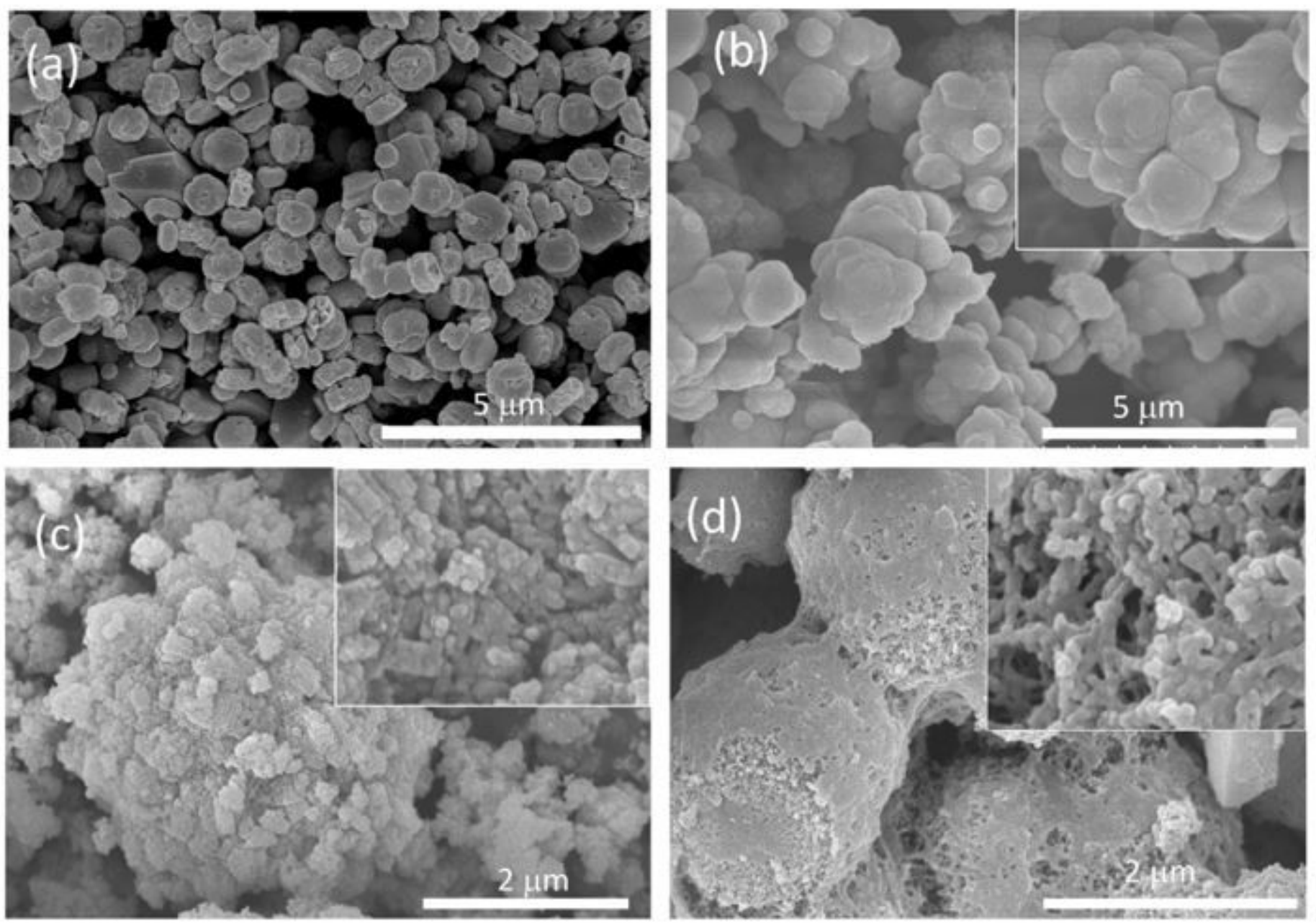

Figure 2

SEM images of synthesized olivine samples: (a) LiFeP04; (b) LiMn0.1Fe0.9P04; (c) LiMn0.2Fe0.8PO4 and (d) LiMn0.3Fe0.7PO4. 

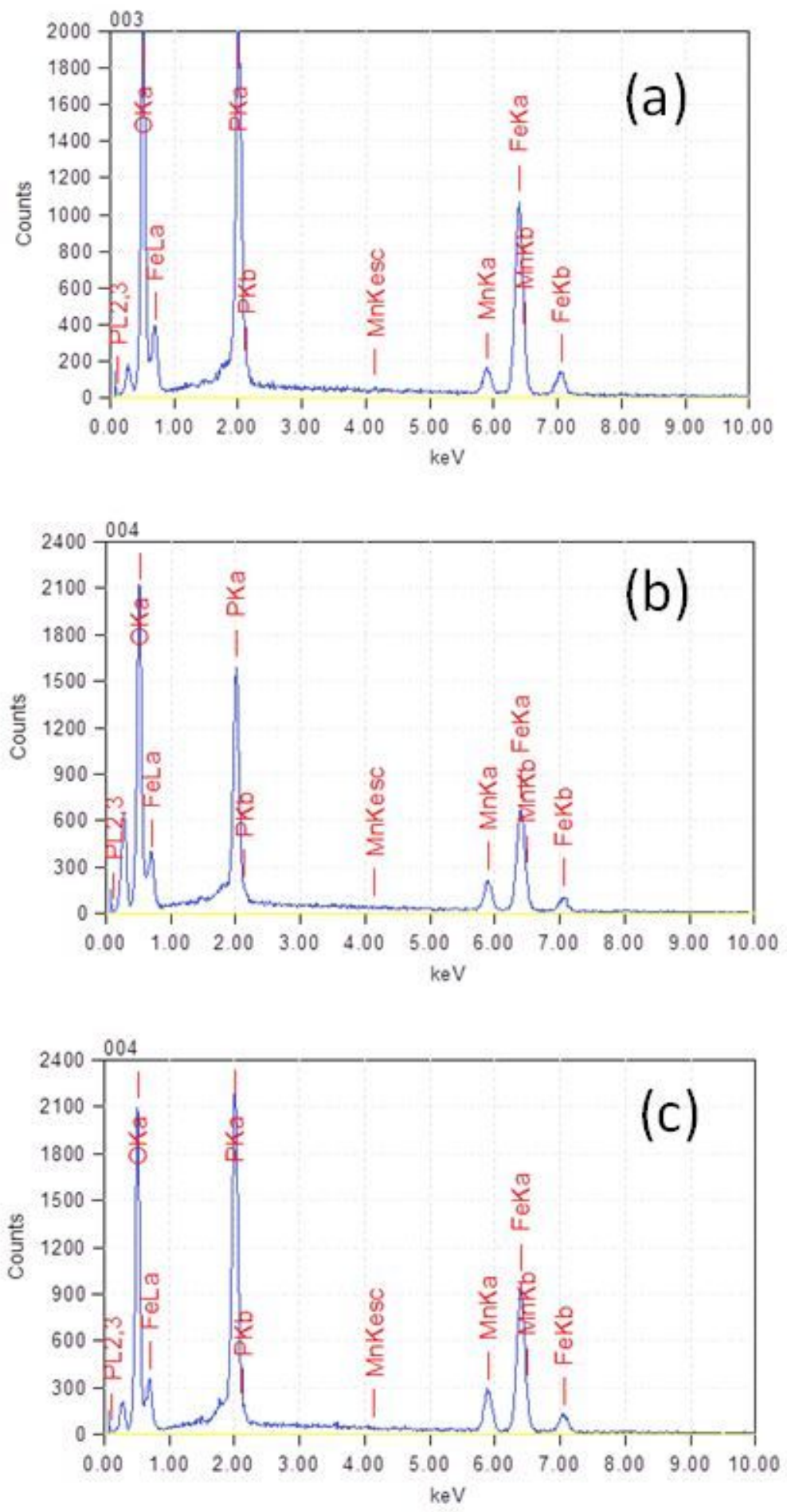

\section{Figure 3}

EDS spectra of Mn-doped olivine samples (a) LiMn0.1Fe0.9PO4; (b) LiMn0.2Fe0.8PO4 and (c) LiMn0.3Fe0.7PO4. 

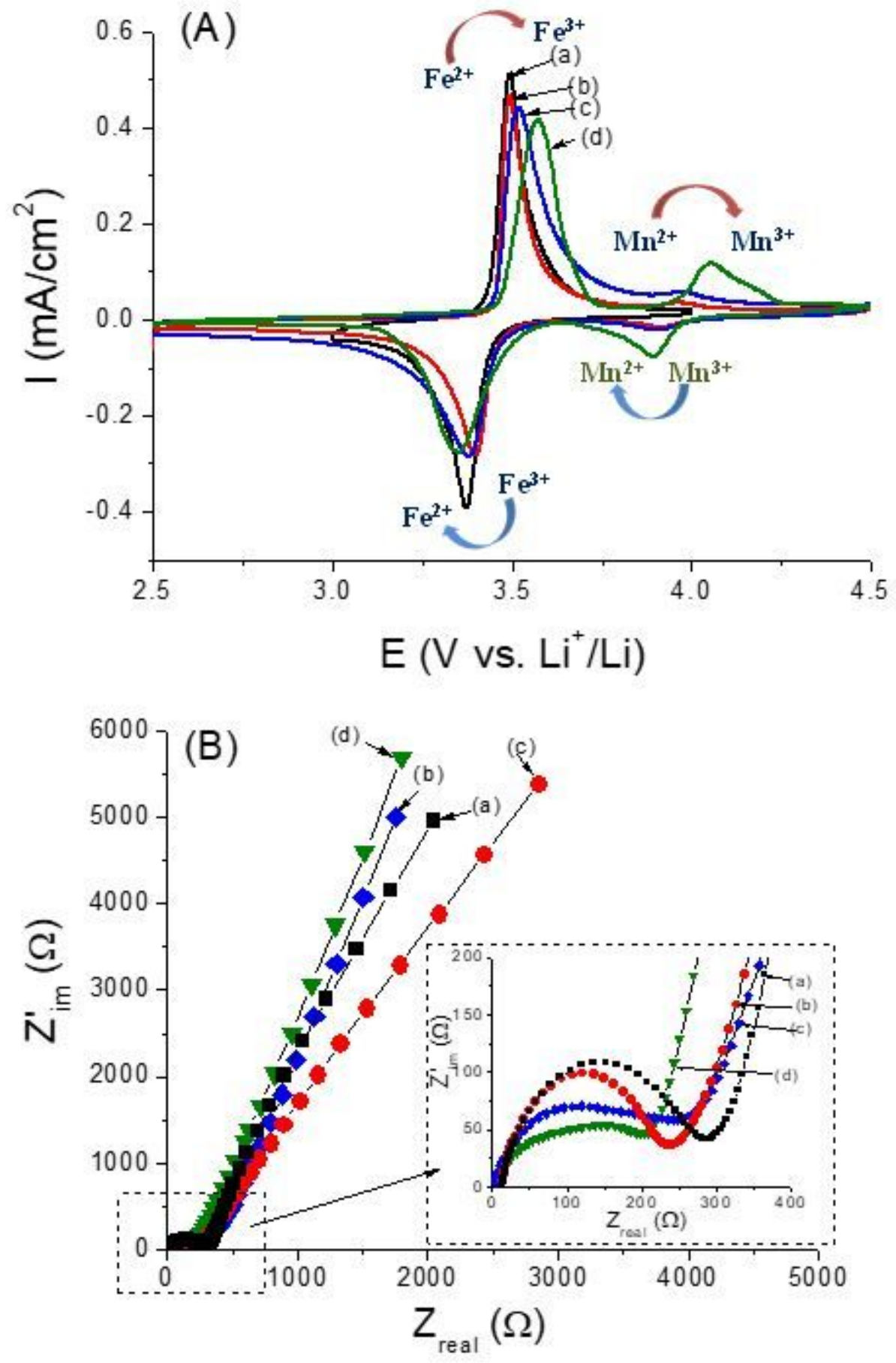

Figure 4

(A) Cyclic voltammograms at a scan rate of $5 \mathrm{mV} \mathrm{s}-1$ and (B) corresponding Nyquist plots of electrochemical impedance spectroscopy (EIS) of synthesized olivine samples: (a) LiFePO4; (b) LiMn0.1Fe0.9PO4; (c) LiMn0.2Fe0.8PO4 and (d) LiMn0.3Fe0.7PO4. Experimental conditions are described in the text. 

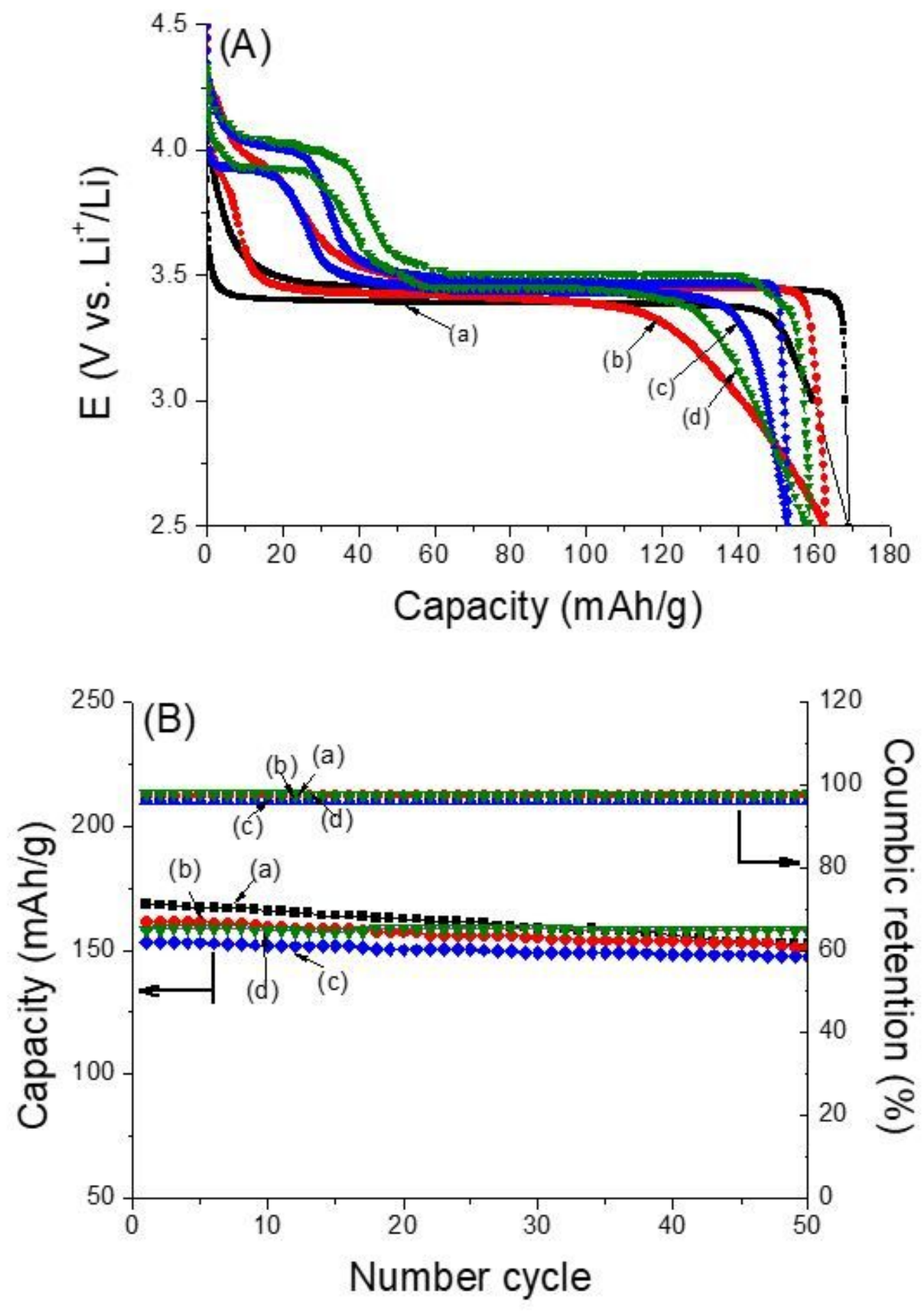

Figure 5

(A) Typical charge/discharge curves and (B) cycling performance upon 50 cycles of olivine samples at a rate 0.1C: (a) LiFePO4; (b) LiMn0.1Fe0.9PO4; (c) LiMn0.2Fe0.8PO4 and (d) LiMn0.3Fe0.7PO4. 


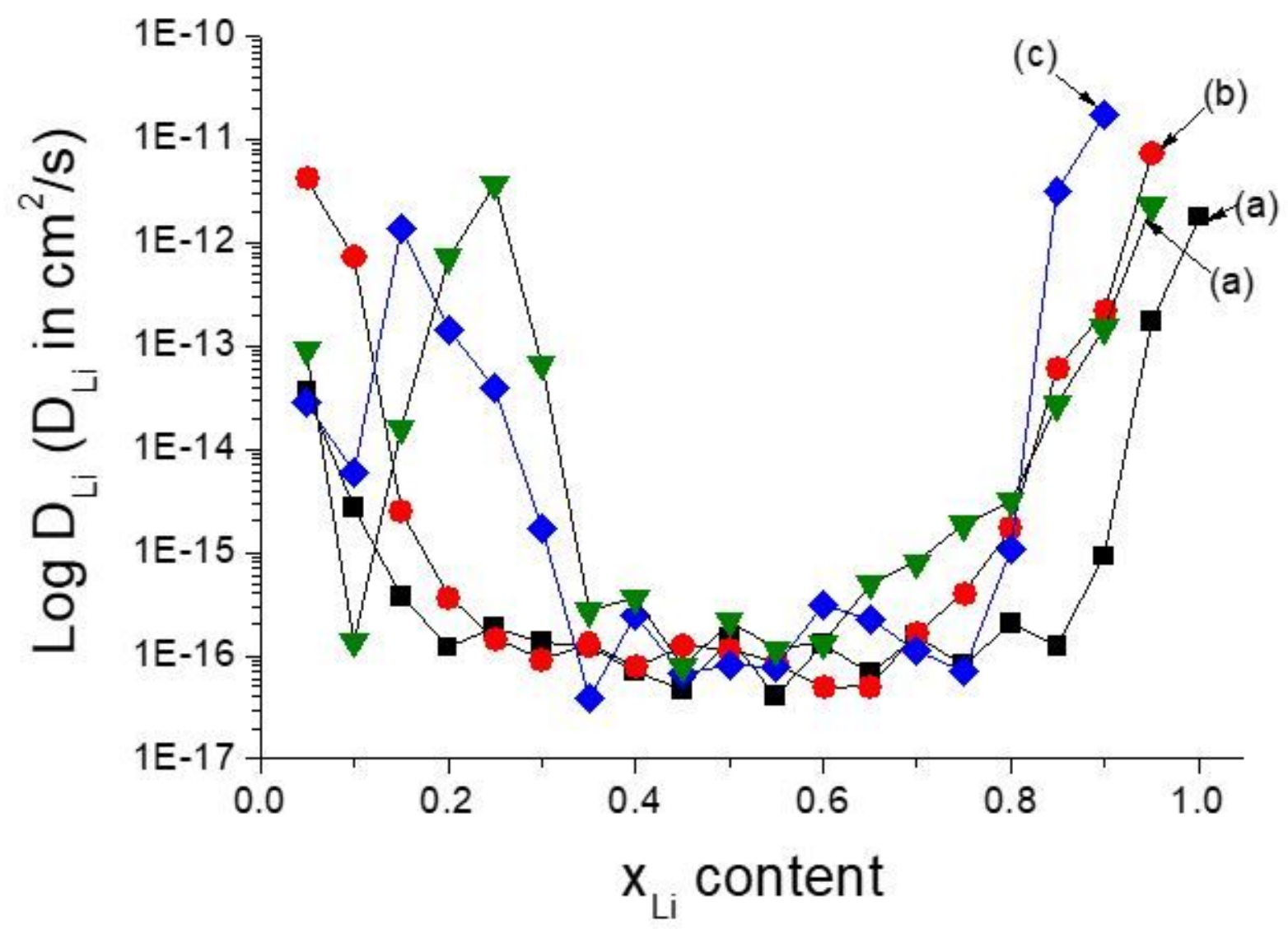

Figure 6

Evolution of DLi as a function of lithium content in olivine samples: (a) LiFePO4; (b) LiMn0.1Fe0.9PO4; (c) LiMn0.2Fe0.8PO4 and (d) LiMn0.3Fe0.7PO4. 